\title{
Psychological recovery after cancer : the place of psychodynamic psychotherapies in French Psycho-Oncology
}

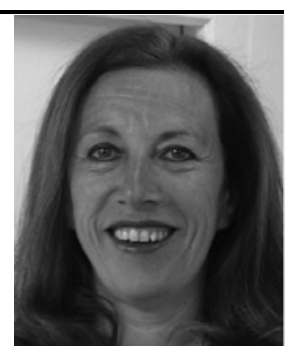

\section{La guérison psychique du cancer : place des psychothérapies psychodynamiques dans la psycho-oncologie française}

\author{
S. Pucheu \\ (C) Springer-Verlag France 2012
}

The aim of any psychotherapy is generally to modify the mental functioning of patients tormented by psychological disorders, or more widely, by any type of psychological and/or relational suffering, in order to improve their capacity to cope with the adversity of life.

Ideally, psychotherapies aspire to get rid of all these troubles.

In psychology as well as in psychiatry, different theories confronted each other using different types of arguments thinking that one is better than the other. Several factors can explain and influence the emergence of psychological troubles or psychological suffering. Cancer and its treatments is one of them.

The different theoretical backgrounds of psychotherapists are often an obstacle to exchanges between practitioners and/or between countries. In France, these theoretical divisions are present and politically crucial in universities with also an effect on the field of psycho-oncology. The French Psycho-Oncology Society (SFPO) and the review "PsychoOncologie" related to this society try to come up to the different French or French-speaking practitioners' expectations and readers in psycho-oncology, included those who refer to the psychodynamic approach.

Actually, how to overcome these clinical and theoretical divisions to improve the global "psycho-oncology" science, when practises and what we could call ideologies are so different in their conceptualizations and in the way they analyse psychological processes?

In September 2010, the first issue specifically dedicated to the theme of psychotherapies in psycho-oncology was

\footnotetext{
S. Pucheu $(\triangle)$

Service de psychologie clinique et psychiatrie de liaison, hôpital européen Georges-Pompidou, 20, rue Leblanc, F-75015 Paris, France

e-mail : sylviepucheu@gmail.com
}

published (Psycho-Oncol. 4(3):143-220). Different methods of psychotherapy were described. We have introduced [20] that different psychotherapies are based on a theory of personality and psychopathology. Therefore, each one proposes different answers to cancer patients who need this help to get rid of their psychological troubles.

In this first issue, Watson and Bultz [22] reminded us that the International Psycho-Oncology Society (IPOS) declaimed in 2010 that distress is the 6th sign in cancer care and highlighted the importance of the screening for distress in cancer patients. In their lead article, they summarized the different kinds of validated psychotherapies applied in psychooncology from an international literature review. In this brief interesting cursus of psychotherapy methods, we observed that there was no mention of psychodynamic or psychoanalytical therapies. In the eighties, Holland and Rowland published the famous "Handbook of Psycho-Oncology" which remains a reference used all over the world for psychooncology. However, to date, the psychodynamic or psychoanalytical approach has neither been described nor been mentioned.

Why don't the psychodynamic references generally take place in the international English-speaking literature in psychology or psychiatry and more particularly in psychooncology. This is only done in very specialized reviews?

In France, one of the problems is that several psychologists working in psycho-oncology refer to this theoretical background $[2,4-8,9,13,19,20]$ and have difficulties to recognize themselves in the official international psychooncology (IPOS) in which this approach has no place. Two reasons could explain the absence of psychodynamic references in most of the international English-speaking "scientific" reviews:

- the first reason is that French psychologists or psychiatrists referring to this theory rarely publish in English, which is very regrettable; 
- the second reason is that international English-speaking reviews don't accept articles referring to psychodynamic or psychoanalytical theories because they don't consider their methods as scientific, that is the method of the "single-case" or research protocols based on qualitative methods from few cases with an elaborate analysis as used by Freud and his successors. Moreover, they don't consider that the "Unconscious", brought to light by Freud is based on scientific proofs. Since a long time in France, many researchers in psychoanalysis tempt to argue the specific scientificity of psychoanalysis $[1,3,10,11,14,21]$.

During the last years, in French psychology, psychiatry and also in psycho-oncology, cognitive and behavioural approaches based on validated "experimental" methods according to their users have been greatly developed all around the world. But it happens that an important number of French psychologists remain very attached to the psychodynamic theoretical background and its qualitative methods are still be learned in several Psychology universities. The psychoanalytical point of view is a part of the French tradition and culture [12].

In this editorial, we choose English-writing to convey something of particular interest regarding the psychodynamic approach in the French Psycho-Oncology.

One can observe that people do not have the same risk of developing a cancer, of pulling through and are different in the subjective experience of both, disease and treatments, according to a great number of factors, including psychosocial ones. Many cancers exist but similarly, many treatments and psychosocial characteristics exist too. This great heterogeneity may explain inter-individual differences in the experience of cancer.

The psychodynamic point of view tries to explain the psychological suffering or the psychological recovery after cancer as per the way the patient went beyond and integrated the undergone potential trauma of cancer and its treatments [15].

This approach is centered on the intrapsychic dimension and the cancer subjective resonance according to the individual personality and history. The observation of several patients confronted to cancer by psychologists and psychiatrists with a psychodynamic orientation now allows highlighting this subjective experience with the psychological processes, which can be considered as common to all patients and those, which are specific and subjective to each one. In France, in the seventies, only psychologists and psychiatrists with psychoanalytical approach began to describe the psychological steps experienced by all patients facing cancer (diagnosis, remission or relapse etc.). Psychologists and psychiatrists referring to this approach use similar underlying concepts to interpret the experience of "cancer event" such as the concepts of "trauma", the Freudian defence mechanisms, the different kinds of anguish or anxiety (castration, separation, division or realistic anxiety). Psychodynamic psychotherapies are oriented on the elaboration of work regarding conflicts or losses, which could not have been elaborated and overcome. The patient, in psychotherapy, is invited to talk about what he wishes in a free association. By this work on oneself, psychotherapy aims to put in relation the present subjective psychological suffering (related to cancer or not) with possible unconscious ancient traumas. In the framework of the psychologist or the psychiatrist with psychodynamic orientation, there is a specific questioning on the intersubjectivity and the place of transference and conter-transference in the therapeutic process $[20,23,24]$.

Nevertheless, the "typical cure" used by psychoanalysts in their private practise is not possible in oncology institutions and practitioners in psycho-oncology have adapted their psychotherapy framework to the specific situation of cancer patients (support and/or psychodynamic psychotherapy) $[9,16,17,20]$.

The authors describe and argue their experience of psychodynamic psychotherapies according to their specific psychoanalytical point of view, which is generally put in relation with the pioneers of psychoanalysis (Freud, Bion, Lacan, Winnicott, etc.).

\section{Let us present a psychodynamic description of the process of psychological recovery after cancer [18]}

Concerning psycho-oncology, firstly, why are some people more or less able to live with the idea of death when this one becomes a potential reality with uncertainty inherent to the cancer experience and this, without apparent difficulties? Secondly, why are some people more or less able to accept and to go beyond the real and/or symbolic losses secondary to this experience?

There is evidence that the severity of the disease and the statistical chance to go through the cancer plays a role in this process of psychological recovery. But, at equal prognosis, some patients are going to recover, others will relapse.

In one hand, for every patient, the diagnosis of cancer is a confrontation to the idea of death but also its reality. Life has an end. This is synonymous of anxiety and distress, even if the cancer has a good prognosis. Self-image and identity are completely shattered. To go beyond this inevitable crisis, there is the necessity of a psychological reorganization. Most of the time, this process is rather unconscious and its aim is to restore the lost continuity and to protect the narcissism. One could define the "psychological recovery" after cancer, whatever the medical prognosis ("physical recovery"), as the capacity to feel again a satisfactory self- 
image, a freedom to make short or long-term plans taking into account the prognosis and the treatment consequences. After cancer, the individual who has reached psychological recovery feels himself or herself the same person, even if a number of things have changed. There is no real specific psychological suffering. So, uncertainty is the first interference of the psychological recovery. Whoever cancer patients are, all of them keep a feeling of vulnerability even after a long time from the diagnosis.

On the other hand, cancer physical recovery is often associated with the loss of physical integrity, particularly organs with high symbolic value, such as sexual organs or organs involved in communication. Even if, mutilating patient is safe, his/her body image may be deeply altered.

In order to reach psychological recovery, the patient has to accept these real and/or symbolic losses. This process is a more or less unconscious work of mourning of what the person was before cancer. From a psychodynamic point of view, psychological recovery is reached when the intrapsychic functioning gets its best level back. That is to say, the individual does not have to limit his or her thoughts and affects to adjust to cancer experience and the mental functioning is flexible.

When narcissism is sufficiently strong, this representation work is relatively spontaneous, sometimes completely hidden by the action of defence mechanisms. So, the patient again finds a satisfactory self-image and the psychological recovery is possible without apparent specific suffering after cancer. This is the case for many patients who apparently want to live again as if cancer experience was not, precisely, experienced. Life must continue as before cancer. Death anxiety has disappeared thanks to defence mechanisms like the splitting of ego and denial. The splitting of ego concerning human mortality is a part of normal life. This was the opinion of Freud at the end of his life. People in general live without thinking to death.

After cancer, as the time from the diagnosis moves away, denial is replaced by emotional suppression which concerns specifically the negative affects like anxiety linked to the idea of death and depression linked to real and/or symbolic losses.

Some patients after cancer need to define new values to their life. It is the positive re-evaluation. Thanks to illness, they now feel that life is important and they wish to achieve plans and to have good relationships with others. For a number of them, this life attitude needs a great effort. Illness has to have sense, to mean something in the individual life as if death anxiety was still too much present. Psychological recovery, in a way, is reached when the person finds again the triteness (banality) of life. Some of these persons might find benefit from a psychodynamic psychotherapy.

Finally, some patients after cancer are unable to go beyond the trauma caused by the illness. Cancer has let irre- versible marks. As indicated above, the cancer trauma needs to be elaborated as any neurotic or psychosomatic symptom. The elaboration is very different from the causal attribution or psychological aetiology or theory of cancer: the patient's work in a free association tries to give a subjective sense to the trauma experienced through cancer and its treatments. Forgotten memories have to be remembered and arranged, in order to give a subjective meaning to the present suffering. This liaison work on one-self generally helps the patient to feel better. Nevertheless, in this particular situation of cancer and very often, of counted time, psychodynamic psychotherapies in psycho-oncology have been adapted. Generally, they are shorter than for patients with only neurotic problems and more centered on the personal resources of adjustment of the patient and the psychotherapist also tries to evaluate and adjust his/her own attitude and the objective of the therapy, with each patient and his/her specific needs (support and/or elaboration). For any psychotherapist with this orientation, there is a need of regular supervision work, individually or in group.

\section{Three cases will illustrate some ways of psychological recovery after cancer and the place of psychodynamic psychotherapy}

\section{Mrs R reached "psychological" recovery without help}

She is 60 years old. She lives alone and is now retired. She has never been married and has no child. Presently, she is going through her 42nd session of chemotherapy for a colon cancer. This treatment is palliative but presently, her health state is stable and she keeps a good physical quality of life. When I ask her how is she and how she feels at the moment, she answers that everything is all right. "I have no choice, $I$ must follow this treatment", "I am passionate so I never get bored. I always have something to do". As she doesn't have any financial problem, she bought a big ancient house which she likes to restore "I have ten years of work" she says. Concerning the idea of death, she talks about her brother who died from a leukaemia 5 years ago and who didn't put his affairs in order for his family. This is not her case. "Everything is in order". She thinks that cancer experience has changed her mind and now she tries to enjoy life much more than before (positive re-evaluation).

Of course, she has no demand of psychotherapy. For her, all the patients she has met had the same fighting spirit and kept courage. Mrs $\mathrm{R}$ has reached psychological recovery without help. She adjusts to illness for the moment. Death perspective is indirectly evoked but not intrusive. Although living alone, she seems to have sufficient narcissistic investments to accept illness and treatment constraints. She can 
invest new plans and the action of defence mechanisms does not impede the mental functioning.

Another question is: what allows Mrs R. to take resilience to deal with cancer and the counted time. It is a too long question but we can imagine that her strong meaning of life, her self-esteem are supported by solid parental and familial identifications that Mrs $\mathrm{R}$ has when she reports her youth. Perhaps, some aspects of her life could be interpreted as neurotic but if we take into account the cancer trauma itself, one could think that psychological recovery has been reached.

\section{Mr D. could never reach "psychological recovery" after cancer}

$\mathrm{Mr} \mathrm{D}$. had a pulmonary cancer. Chemotherapy was proposed after an operation. But cancer spread to the pleura. The prognosis was serious. Mr D is 53 years old. He is divorced and has three children of 25,18 and 16 years old respectively. He is a cook and works very hard. He didn't pay attention to the first symptoms because he was very tired and in spite of smoking from the age of 14 . From the day of the diagnosis to the last days of his life, eight months later, anxiety was intrusive and nothing could relieve him, neither psychotropic drugs which were prescribed at high proportion, nor psychotherapy proposed by palliative care psychologist, nor by family and friendly support. Anxiety was always present. The psychic regression was very important. Contrary to what he was before, he was unable to take charge of himself and was totally inactive, unable to keep his parental function. He never talks about death and couldn't put his affairs in order, but said regularly "I am going to cure" in a plated way. At each consultation with the oncologist, the anxiety was extreme and he had all the physical signs of it, but he never asked the oncologist on the prognosis. Physical pain and psychological suffering were difficult to differentiate all along the duration of the disease.

Why couldn't Mr D reach psychological recovery? Difficult question, but we learned that he was depressed before illness. The disease appeared at a moment when he would have liked to give a new sense to his life after suffering two setbacks in his sentimental life. This could be interpreted as the repetition of negative attachment during his childhood. Although he could profit by a psychoanalytical therapy before cancer promotion, all the gains of this psychotherapy seem to be swept away. The counted time was unbearable, ever this could never be pronounced. Mental elaboration was impossible and thoughts process was staggered. Activity, professional recognition played an important role and the sudden inactivity has let him in front of a profound narcissistic wound. Here, ancient traumas, lack of love during childhood were reactivated by cancer trauma and death perspective even in the past psychodynamic psychotherapy. As well, present social support could not compensate the past wounds. Perhaps time was too short to allow and continue the psychotherapeutic work started before.

This means also that psychotherapists have sometimes to face their powerlessness to relieve psychological suffering.

\section{Mrs P. and the benefit of psychodynamic psychotherapy}

The first time I met Mrs P., she was fifty years old and in remission of a melanoma situated under the breast. Since a few months, she had a preventive cure of chemotherapy after the surgery. At the moment, she is deeply depressed. In her talk, cancer is not to the fore. For her, depression is linked to different events, including cancer, which followed one another. Recently, she has been disbanded. Moreover, she hasn't recovered from her divorce, ten years earlier. She was married during fifteen years and she thought everything was all right because her husband was a silent man who never complained. It was the best period of her life with no question and an emotional security. Two sons were born of their union. Mrs P. thinks her eldest one is like his father. She used to be close to him, but their relation is now more distant. This son has no particular problem. In return, she is extremely preoccupied by her second son and her depression is very much explained, for her, by this situation. He is suffering from drug addiction since his teenage years. As she is, he is also very depressed and has never accepted his father's departure following his parents' divorce. She had always been in a "fusional" relationship with her son. Both tried several suicide attempts. Moreover, Mrs P. is frightened everyday that the police will come again in their apartment to look for drugs, as it happened once. At the beginning of the psychotherapy, Mrs P. didn't see what can keep her for life except her obligation to take care of her son and her mother, who both, need her. One year and a half, at a rate of once a week, were necessary to Mrs P. to achieve a work on herself in order to reach psychological recovery. Even if death anxiety was out of its place, it reactivated several traumas and aroused the psychological suffering and the inevitable question of death idea associated with cancer experience "What is the reason of my life?".

For Mrs P., this was a difficult question, because her narcissism was weakened for a long-time. In short, the beginning of Mrs P.'s life was the worst moment of her life because of the war. Her father was mobilised and her mother had to work in their coffee bar. So she was placed at an aunt's house. She felt that she had not been wished by her parents. After the war, she went back with her parents but they divorced when she was 7 , because of violent conflicts. Her father was alcoholic and beated her mother. She felt very ashamed of the divorce and at school, preferred to tell that her father was dead. Five years later, her father died in reality so she felt a strong guilt of having had such a thought. She 
was unable to attend his burial. The psychological suffering due to her parents' divorce and the guilt of having unconsciously wished her father death kept her to tail of the underlying problem of her couple. When her second son was born, he had not been wished because she was satisfied with her eldest son. So again, she felt unconscious guilt, which induced her to overprotect her son not to repeat her own difficult childhood. But at the same time, she turned away from her husband and partly created their separation. Gradually, depression affects disappeared as the psychological work came on. She could take a saving distance with her son who, on his side, was undergoing a treatment for addiction. She read a lot of books, including psychoanalytical theory, which helped her to understand the relationships between parents and children. She found a new work in a charitable organisation that allowed her to find again trust in herself.

In a psychoanalytical point of view, this woman's story could have several interpretations. Here, what is important is the own or subjective meaning that this woman could give to her life, which is very different from a psychological aetiology of cancer. Cancer takes part of this story but is not explained by this story even if, perhaps, without depression, she would have paid more attention to the evolution of her beauty spot under the breast and detected her cancer earlier.

\section{In conclusion...}

This second issue on psychotherapies in psycho-oncology presents different approaches without yet being exhaustive.

The work continues...

\section{References}

1. Attigui P (eds) (2009) Psychopathologie et psychanalyse: éléments d'une épistémologie de la psychanalyse. Les Cahiers de 1'ED 139 : Connaissance, Langage et Modélisation. Presses Universitaires de Paris Ouest Nanterre La Défense.

2. Bacqué M-F (2005) Pertes, renoncements et intégrations: processus de deuil dans les cancers. Rev Fr Psycho-Oncologie 2: $117-123$

3. Bertrand M (2001) Trois défis pour la psychanalyse: clinique, théorie, psychothérapie. Dunod, Paris
4. Cavro E, Bungener C, Boy A (2005) Le syndrome de Lazare: une problématique de la remission. Réflexion autour de la maladie cancéreuse chez l'adulte. Rev Fr Psycho-Oncologie 2: 74-79

5. Célérier M-C (1997) Psychothérapie des troubles somatiques. Dunod, Paris

6. De M’Uzan M (1977) Le travail du trépas. In: De l'art à la mort. NRF, Paris, pp158-163

7. Derzelle M (2007) Fatigue et métamorphose de l'image du corps chez les patients atteints du cancer: entre repli du corps et nécessaire travail de la depression. Psycho-Oncologie 1:13-18

8. Ferrant A, Bonnet V (2003) Blessure narcissique et Ideal du moi. La figure du vaillant petit soldat. Rev Fr Psycho-Oncology 3: $81-85$

9. Ferrant A (2004) Psycho-oncologie et travail du psychanalyste. Rev Fr Psycho-Oncologie 1: 50-56

10. Fishman G (dir.) (2009) L'évaluation des psychothérapies et de la psychanalyse. Masson, Issy-les-Moulineaux

11. Gori R, Hoffmann C, Douville O (2002) Sur les conditions de la recherche en psychanalyse. Psychologie Clinique 13: 7-25

12. Jeanclaude C (2010) Freud et son héritage. Rappel des fondamentaux freudiens de la psychanalyse comme discipline indépendante. De Boeck, Bruxelles

13. Pedinielli J-L (1994) Hypothèse d'un travail de la maladie. Cliniques Méditerranéennes, 41/42: 169-189

14. Perron R (2010) La raison psychanalytique. Dunod, Paris

15. Potamianou A (2001) Le traumatique: répétition et élaboration. Dunod, Paris

16. Pucheu S (1992) Entre panser le corps et penser l'esprit: le psychologue en cancérologie. Revue de Médecine Psychosomatique 29: 101-112

17. Pucheu S, Machavoine J-L (2002) Construction d'un cadre d'intervention du psychologue en oncologie: perspective psychanalytique. Rev Fr Psycho-Oncologie 1/2: 24-30

18. Pucheu S (2004) La guérison psychique du cancer ou le retour de l'harmonie du moi. Rev Fr Psycho-Oncologie 2: 61-64

19. Pucheu S (2008) L'adaptation comme processus subjectif dynamique de réorganisation psychique : l'exemple de trois patients atteints de cancer du côlon. Psycho-Oncologie 2: 164-178

20. Pucheu S (2010) Psychothérapies en oncologie hospitalière: cadres, références et pratiques. Psycho-Oncologie, 4: 151-158

21. Santiago-Delefosse M, Rouan G (eds) (2001) Les méthodes qualitatives en psychologie. Dunod, Paris

22. Watson M, Bultz B.D (2010). Distress, the $6^{\text {th }}$ vital sign in cancer care. Caring for patients emotional needs: what does this mean and what helps? Psycho-oncologie, 4:159-163

23. Wallerstein RS (2006) Psychoanalytic therapy research :its history, present status, and projected future. In Psychodynamic diagnosis manual. Silver Spring. Alliance of Psycoanalytical Organizations.

24. Westen D, Novotny C,Thompson-Brenner H(2004) The empirical status of empirically supported psychotherapies :assumption, findings, and reporting in controlled clinical trials. Psychol Bull $4: 631-63$ 